\title{
Combined use of CA 125 and Inhibin as tumor marker for detection of ovarian cancer in comparison to $\mathrm{CA} 125$ or Inhibin alone
}

\author{
Avinash P. Dubbewar ${ }^{1}$, B. Pathak ${ }^{2 *}$, Manas Biswas ${ }^{3}$, Gunjan Malhotra ${ }^{4}$
}

\begin{abstract}
${ }^{1}$ Department of Obstetrics and Gynecology, Military Hospital Devlali, Nashik-422401, Maharashtra, India ${ }^{2}$ Department of Obstetrics and Gynecology, Command Hospital Air Force Bangalore, Bangalore, Karnataka, India ${ }^{3}$ Department of Obstetrics and Gynecology, Military Hospital Roorkee, Roorkee-247667, Uttarakhand, India ${ }^{4}$ Department of Obstetrics and Gynecology, Armed Forces Clinic, New Delhi-110011, India
\end{abstract}

Received: 15 November 2017

Accepted: 17 November 2017

\section{*Correspondence:}

Dr. B. Pathak,

E-mail: bpathak_go@yahoo.co.in

Copyright: ( ) the author(s), publisher and licensee Medip Academy. This is an open-access article distributed under the terms of the Creative Commons Attribution Non-Commercial License, which permits unrestricted non-commercial use, distribution, and reproduction in any medium, provided the original work is properly cited.

\begin{abstract}
Background: Ovarian cancers are diagnosed at an advanced stage. Early diagnosis is the key to reduce death from ovarian cancer. The present study is an effort to assess the suitability of combined test using CA 125 and Inhibin for early diagnosis of ovarian cancer as compared to CA125 or Inhibin alone.

Methods: Fifty women with clinical suspicion of ovarian malignancy attending Gynae OPD were enrolled. All of these women were subjected to estimation of CA 125 and Inhibin levels prior to surgical intervention. A value of 35 $\mathrm{IU} / \mathrm{ml}$ was taken as positive for CA 125 . For Inhibin, $10.5 \mathrm{pg} / \mathrm{ml}$ was taken as cut off for premenopausal patients, whereas, any detectable assays were taken as positive for postmenopausal patients. The results were analyzed after establishing final histopathology of the disease.

Results: Out of 50 patients recruited, $30(60 \%)$ were found to have carcinoma ovary and 20 (40\%) were found to have benign diseases. Out of 30 cases of carcinoma ovary, CA125 was raised in $81 \%$ of cases and Inhibin was raised in $78 \%$ of cases. For detection of carcinoma ovary, CA 125 was found to have a sensitivity of $90 \%$ and specificity of $60 \%$ with a positive predictive value of $77 \%$ and negative predictive value of $80 \%$ which were statistically significant. Sensitivity and specificity of serum Inhibin for the same was $86.6 \%$ and $20 \%$ respectively. The positive and negative predictive value were $61.9 \%$ and $50 \%$, which were not statistically significant. Sensitivity and specificity of combined CA125 and Inhibin were $100 \%$ and $30 \%$ respectively. The positive and negative predictive value were $68.1 \%$ and $100 \%$ respectively, which were statistically significant.

Conclusions: Combined use of CA125 and Inhibin has got better sensitivity and specificity in detection of ovarian cancer in comparison to CA 125 or Inhibin used alone.
\end{abstract}

Keywords: CA 125, Epithelial, Inhibin, Mucinous, Ovarian, Serous

\section{INTRODUCTION}

More women die of ovarian cancer than of all other gynaecologic cancers combined. These cancers are typically diagnosed at an advanced stage, after the cancer has spread throughout the abdominal cavity. Screening for ovarian cancer is difficult since there is no suitable biochemical marker for its early detection. Small tumors can be detected only by ultrasonography.

CA-125, a protein expressed on the cell membrane of normal ovarian tissue, is elevated in some women with ovarian cancer, especially those with serous cancer. ${ }^{1}$ It may also be elevated in women with nongynecological 
cancers, liver disease, acute pancreatitis, renal failure and in some seemingly normal women. ${ }^{2}$

Inhibin, a glycoprotein secreted by the granulosa cells of the ovary is secreted throughout the menstrual cycle and during pregnancy but not in postmenopausal women. Women with granulosa-cell tumors of the ovary have elevated serum Inhibin concentrations and measurements of this hormone are useful marker for persistent or recurrent granulosa-cell tumors. ${ }^{3}$

CA125 is effective in detecting serous ovarian cancers, whereas Inhibin is effective in detecting the mucinous and granulosa cell cancer. The present study is an effort to assess the suitability of combined test using Inhibin and CA 125 to diagnose patients with ovarian cancer.

\section{METHODS}

Fifty women with clinical suspicion of ovarian cancer attending Gynae OPD were enrolled in study. Suspicion of malignancy was based on clinical finding and ultrasonography/CT scan/MRI finding. Patients already undergone surgery or neo-adjuvant chemotherapy were excluded from the study. All of women, consented for the study, were subjected to estimation of serum Inhibin and CA125 levels using ELISA technique.

Serum Inhibin was done on D1 to D5 of cycle in premenopausal patients to avoid bias of fluctuating values of Inhibin during different phases of menstrual cycle. A value of $10.5 \mathrm{pg} / \mathrm{ml}$ was taken as cut of value for premenopausal patients. ${ }^{4,5}$ In postmenopausal patients, any detectable assay of Inhibin was taken as positive. In case of CA125, $35 \mathrm{IU} / \mathrm{ml}$ was taken as positive. ${ }^{2,6,7}$

The cases were managed as per standard treatment protocol. Once the final histopathological diagnosis of all the cases were established, the preoperative CA 125 and Inhibin levels were compared with final histopathology.

\section{RESULTS}

Total of 50 patients were included in study after applying inclusion and exclusion criteria. Total of 27 women were premenopausal and 23 were post-menopausal. Age wise distribution of cases is shown in Table 1 .

Table 1: Age-wise distributions of cases.

\begin{tabular}{|lll|}
\hline Age in years & Benign & Malignant \\
\hline $21-30$ & $1(2 \%)$ & $1(2 \%)$ \\
\hline $31-40$ & $1(2 \%)$ & $3(6 \%)$ \\
\hline $41-50$ & $10(20 \%)$ & $12(24 \%)$ \\
\hline $51-60$ & $7(14 \%)$ & $10(20 \%)$ \\
\hline $61-70$ & $1(2 \%)$ & $1(2 \%)$ \\
\hline$>70$ & 0 & $3(6 \%)$ \\
\hline Total & $20(100 \%)$ & $30(100 \%)$ \\
\hline
\end{tabular}

Most the benign tumours were seen in the $3^{\text {rd }}$ and $4^{\text {th }}$ decade of life, while the malignant tumour had an age distribution mostly in the $5^{\text {th }}$ and $6^{\text {th }}$ decade of life (Table 1).

Out of 50 patients recruited, 30 were found to have carcinoma ovary and 20 were found to have benign diseases. Success rate of finding a malignancy in suspected case of carcinoma ovary was 60 percent on the basis of final histopathological report.

Out of 30 patients of carcinoma ovary, 27 patients were epithelial ovarian cancer, 01 case each of undifferentiated adenocarcinoma, granulose cell tumour and pseudomyxoma peritonei. In epithelial ovarian cancer 18 were serous cystadenocarcinoma cases, 07 were mucinous cystadenocarcinoma cases and 02 cases of mixed epithelial cancer (Figure 1).

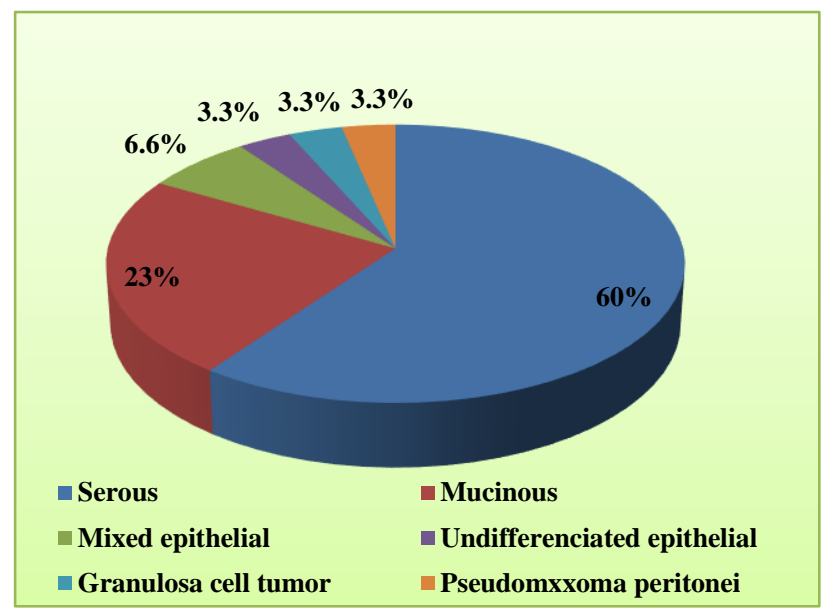

Figure 1: Histopathological distribution of malignant cases.

In benign conditions, out of 20 cases, 10 cases were benign ovarian cysts and 10 cases were benign pelvic conditions. Distribution of benign ovarian cysts and other pelvic conditions are shown in Figure 2 and Figure 3.

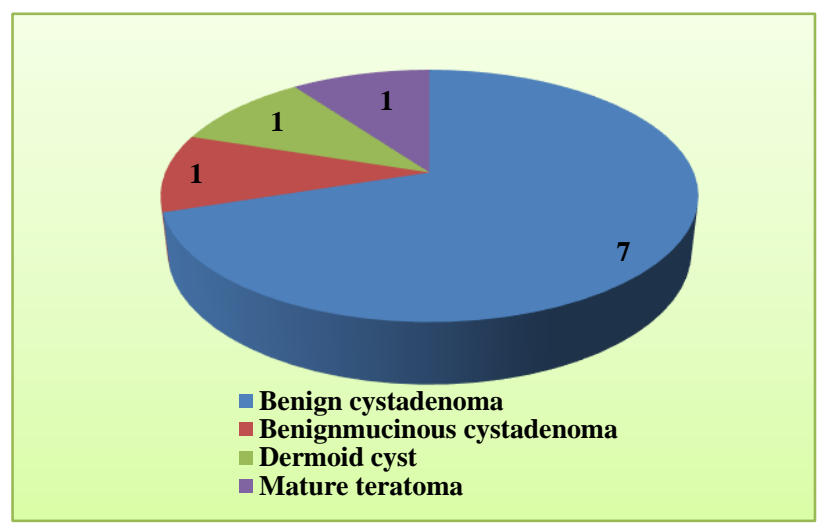

Figure 2: Distribution of benign ovarian cyst. 
CA125 was raised in $94 \%$ of serous carcinoma, $71 \%$ of mucinous carcinoma and all cases of mixed epithelial carcinoma, undifferentiated carcinoma, granulosa cell carcinoma but not in pseudomyxoma peritonei. It was also raised in $40 \%$ of benign conditions (Table 2 ).

Serum Inhibin was raised in $61 \%$ of serous carcinoma, $100 \%$ of mucinous carcinoma, $50 \%$ in mixed epithelial carcinoma cases, and found to be raised in all single case of undifferentiated, granulosa cell tumour, pseudomyxoma peritonei (Table 2). Inhibin was raised in $80 \%$ of benign diseases. After combining the results of both serum Inhibin and CA125, either one of them or both of them were raised in all carcinoma cases with detection rate of $100 \%$. It was also raised in $70 \%$ cases of benign conditions.

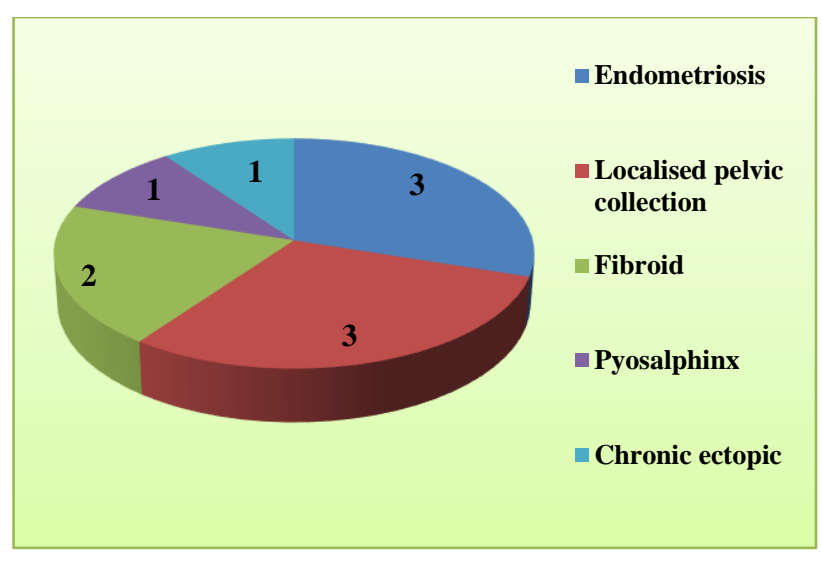

Figure 3: Distribution of benign pelvic conditions.

Table 2: Level of CA 125 and Inhibin in different types of ovarian carcinoma.

\begin{tabular}{|lll|llll|}
\hline & Serous & Mucinous & Mixed & Undifferentiated & Granulosa & Pseudomyxoma Peritonei \\
\hline Cases & 18 & 07 & 02 & 01 & 01 & 01 \\
\hline Raised Inhibin & $11(61 \%)$ & $07(100 \%)$ & $01(50 \%)$ & $01(100 \%)$ & $01(100 \%)$ & $01(100 \%)$ \\
\hline Raised CA125 & $17(94 \%)$ & $05(71 \%)$ & $02(100 \%)$ & $01(100 \%)$ & $01(100 \%)$ & 00 \\
\hline
\end{tabular}

Table 3: Statistical analysis of results of CA 125, Inhibin and both combined.

\begin{tabular}{|c|c|c|c|c|c|c|c|c|c|c|c|}
\hline \multirow{2}{*}{ Markers } & \multicolumn{2}{|c|}{ Normal values } & \multicolumn{2}{|c|}{ Raised values } & \multirow{2}{*}{$\begin{array}{l}\text { Sn } \\
(\%)\end{array}$} & \multirow{2}{*}{$\begin{array}{l}\text { Sp } \\
(\%)\end{array}$} & \multirow{2}{*}{$\begin{array}{l}\text { PPV } \\
(\%)\end{array}$} & \multirow{2}{*}{$\begin{array}{l}\text { NPV } \\
(\%)\end{array}$} & \multirow{2}{*}{$\begin{array}{l}\text { FP } \\
(\%)\end{array}$} & \multirow{2}{*}{$\begin{array}{l}\text { FN } \\
(\%)\end{array}$} & \multirow{2}{*}{$P$ value } \\
\hline & Benign & Cancer & Benign & Cancer & & & & & & & \\
\hline CA 125 & $\begin{array}{l}12 / 20 \\
(60 \%)\end{array}$ & $\begin{array}{l}03 / 30 \\
(10 \%)\end{array}$ & $\begin{array}{l}08 / 20 \\
(40 \%)\end{array}$ & $\begin{array}{l}27 / 30 \\
(90 \%)\end{array}$ & 90 & 60 & 77.143 & 80 & 40 & 10 & 0.001 \\
\hline Inhibin & $\begin{array}{l}04 / 20 \\
(20 \%)\end{array}$ & $\begin{array}{l}04 / 30 \\
(13.3 \%)\end{array}$ & $\begin{array}{l}16 / 20 \\
(80 \%)\end{array}$ & $\begin{array}{l}26 / 30 \\
(86.6 \%)\end{array}$ & 86.66 & 20 & 61.9 & 50 & 80 & 13.3 & 0.529 \\
\hline $\begin{array}{l}\text { Both } \\
\text { CA } 125 \text { and } \\
\text { Inhibin }\end{array}$ & $\begin{array}{l}06 / 20 \\
(30 \%)\end{array}$ & 00 & $\begin{array}{l}14 / 20 \\
(70 \%)\end{array}$ & $\begin{array}{l}30 / 30 \\
(100 \%)\end{array}$ & 100 & 30 & 68.182 & 100 & 70 & 00 & 0.003 \\
\hline
\end{tabular}

Out of 30 cases of carcinoma ovary, CA125 was raised in $90 \%$ of cases and Inhibin was raised in $86.6 \%$ of cases (Table 3).

\section{DISCUSSION}

In our study, the incidence of detection of carcinoma ovary after final histopathological report was $60 \%$. Ovarian tumour was found in all age groups. Most of the benign tumours were seen in the $3^{\text {rd }}$ and $4^{\text {th }}$ decade of life, while the malignant tumour had an age distribution mostly in the $5^{\text {th }}$ and $6^{\text {th }}$ decade of life (Table 1). These findings are in agreement with that of many workers such as Vora and Bhargav et al, Jagadeshwari et al, Ramchandran et al. ${ }^{8-10}$

In present study, CA125 was found raised in $94 \%$ of serous and $71 \%$ of mucinous ovarian carcinoma. (Table 2). CA125 was found to be raised in $40 \%$ of benign and $90 \%$ of malignant cases (Table 3). CA 125 shows sensitivity of $90 \%$ and specificity of $60 \%$ for detection of ovarian malignancy. The positive predictive value and negative predictive value were $77 \%$ and $80 \%$ respectively, making $\mathrm{P}$ value of 0.001 , which was significant (Table 3).

In 2002, Schutter et al using cut-off value of CA 125 to be $35 \mathrm{IU} / \mathrm{mL}$, he found a sensitivity of CA 125 to be $81 \%$ and positive predictive value to be $72 \% .{ }^{11}$ Stakes et al found CA 125 to be $86 \%$ for risk of ovarian cancer algorithm and specificity of $98 \%$ for CA 125 component of algorithm. ${ }^{12}$ Sensitivity and positive predictive value being $83 \%$ and $16 \%$ respectively. Buys et al found a positive predictive value of $4 \%$ for CA 125 alone and $26.5 \%$ for abnormal CA 125 combined with transvaginal sonography. ${ }^{13}$

In present study serum Inhibin was found to be raised in $80 \%$ of benign and $86.6 \%$ of malignant cases. Serum Inhibin was found raised in $61 \%$ of serous carcinoma, $100 \%$ of mucinous, $50 \%$ of mixed type and $100 \%$ of each case of granulose cell, undifferentiated and 
pseudomyxoma peritonei. Sensitivity and specificity of serum Inhibin was $86.6 \%$ and $20 \%$ respectively for detection of carcinoma ovary. The positive and negative predictive value were $61.9 \%$ and $50 \%$ respectively, making $\mathrm{P}$ value of 0.529 , which was not significant (Table 3).

Jobling et al has shown more detailed survey of the usefulness of Inhibin measurements in the follow-up of 27 patients with granulose cell tumours, which was subsequently confirmed by Boggess et al and Petraglia et al. ${ }^{14}$ Healy et al showed that serum total Inhibin was also elevated in $70 \%$ of mucinous epithelial cancers, but much less frequently in serous and endometrioid subtypes of ovarian epithelial carcinoma. ${ }^{15}$ In the present study, combined CA125 and serum Inhibin was found to be raised in $70 \%$ of benign and $100 \%$ of malignant cases. Sensitivity of combined assay was $100 \%$ for detection of carcinoma ovary and specificity was $30 \%$. The positive predictive value was $68.1 \%$ and negative predictive value was $100 \%$ making $\mathrm{P}$ value of 0.003 , which was statistically significant.

Robertson DM et al has mentioned in his study that Inhibin complements another ovarian cancer marker, CA125 in that each performs better with different subtypes of ovarian cancer. ${ }^{16}$ Inhibin is the better marker for granulosa cell tumour and mucinous epithelial carcinoma subtype, while CA125 is much better at detecting the serous and endometrioid subtypes of epithelial carcinoma. The two markers together detect more cases of ovarian cancer than each separately, with improved sensitivity and specificity. In this particular series, the two serum markers detected $95 \%$ of the ovarian tumours with $95 \%$ specificity.

\section{CONCLUSION}

Both CA 125 and Inhibin are useful in detecting serous subtype and granulosa cell and mucinous subtypes of ovarian cancers respectively. Combined use of CA125 and Inhibin showed better results in early detection of ovarian cancer in comparison to either CA125 and serum Inhibin alone. However, larger studies are required to formulate an algorithm incorporating various cut-offs of both CA 125 and Inhibin for early detection of various subtypes of ovarian malignancies.

Funding: No funding sources Conflict of interest: None declared

Ethical approval: The study was approved by the Institutional Ethics Committee

\section{REFERENCES}

1. Bast RC, Klug TL, St John E. A radioimmunoassay using a monoclonal antibody to monitor the course of epithelial ovarian cancer. N Engl J Med. 1983;309:8837 .

2. Montag TW. Tumor markers in gynecologic oncology. Obstet Gynecol Surv. 1990;45:94-105.

3. Lappohn RE, Burger HG, Bouma J, Bangah M, Krans $\mathrm{M}$, de Bruijn HWA. Inhibin as a marker for granulosacell tumors. N Engl J Med. 1989;321:790-3.

4. Robertson DM, Pruysers E, Burger HG, Jobling T, McNeilage J, Healy D. Inhibin and ovarian cancer. Molecular Cellular Endocrinol. 2004;225(2004):65-71.

5. Lappohn RE, Burger HG, Bouma J, Bangah M, Krans $\mathrm{M}$, de Bruijn HWA. Inhibin as a marker for granulosacell tumors. N Engl J Med. 1989;321:790-3.

6. Jacobs I, Davies AP, Bridges J. Prevalence screening for ovarian cancer in postmenopausal women by CA 125 measurement and ultrasonography. $\mathrm{Br}$ Med $\mathrm{J}$. 1993;306(6884):1030-4.

7. Zurawski VR, Sjovall K, Schoenfeld DA, Broderick SF, Hall P, Bast RC, et al. Prospective evaluation of serum CA 125 levels in a normal population, phase I: the specificities of single and serial determinations in testing for ovarian cancer. Gynecol Oncol. 1990;36(3):299-305.

8. Vora, Bhargava VL. Clinicopathological study of ovarian neoplasms. J Obst Gynae India. 1969;19:358.

9. Reddy JN, Rao S, Shrinivas. Incidence of ovarian tumour. J Obst Gynae India. 1971;21:727.

10. Ramachandran G, Hiralal KR, Chinnama KK. Ovarian neoplasms. J Obst Gynae India. 1971;29:309.

11. Schuter EMJ, Davelar EM, Van Kamp GJ. The differential diagnostic potential of a panel of tumour markers in patient with pelvic masses. Am J Obstet Gynaecol. 2002;187(2):385-92.

12. Stakes SJ, Menon U, Donald MN. Calculation of the risk of ovarian cancer from serial CA 125 level for preclinical detection in postmenopausal women. J Clin Oncol. 2003;15:2065-103.

13. Buys SS, Partridge E, Greene MH. PCLO Project team. Ovarian cancer screening in the prostate, lung, colorectal and ovarian (PLCO) cancer screening trial: findings from the initial screen of a randomized trial. Am J Obstet Gynaecol. 2005;193:1630-9.

14. Jobling T, Mamers P, Healy DL, McLachlan V, Burger HG, Quinn M, et al. A prospective study of inhibin in granulosa cell tumors of the ovary. Gynecol Oncol. 1994;55:285-9.

15. Healy DL, Burger HG, Mamers P, Jobling T, Bangah M, Quinn $M$, et al. Elevated serum inhibin concentrations in postmenopausal women with ovarian tumours. N Eng J Med. 1993;329:1539-42.

16. Robertson DM, Pruysers E, Jobling T. Inhibin as a diagnostic marker for ovarian cancer. Cancer Letters. 2007;249(1):14-7.

Cite this article as: Dubbewar AP, Pathak B, Biswas M, Malhotra G. Combined use of CA 125 and Inhibin as tumor marker for detection of ovarian cancer in comparison to CA 125 or Inhibin alone. Int J Reprod Contracept Obstet Gynecol 2017;6:5313-6. 